\title{
LA HAGIOGRAFÍA MEDIEVAL, UNA PARTICULAR HISTORIOGRAFIA. UN BALANCE DEL CASO HISPANO
}

\author{
POR
}

\author{
Ángeles García de La Borbolla \\ Universidad de Navarra
}

\begin{abstract}
Resumen
La hagiografía se puede considerar como un instrumento para hablar de la única y verdadera fuente de santidad. A pesar de la continuidad de este mensaje, se advierten cambios en la manera de hacerlo llegar al receptor. Estas fuentes revelan una serie de manifestaciones, gestos, palabras, que traslucen una mentalidad que conecta al individuo con un grupo, y que está integrada por creencias, valores y virtudes.
\end{abstract}

\begin{abstract}
ARSTRACT
The hagiography can be considered as an instrument to speak of the only one and real source of holiness. In spite of the continuity of this message, there are changes in the way of making to arrive it to the receiving. These sources reveal manifestations, gestures, words, that express a mentality that connects the individual person with a group, and it is mixed by beliefs, securities and virtues.
\end{abstract}

\section{INTRODUCCIÓN}

Si la hagiografía, entendida como disciplina científica, es la ciencia histórica y crítica que trata sobre los santos, un documento hagiográfico sería aquel que informase sobre estas figuras y sobre su culto. Sin embargo, en sentido estricto este último término debe reservarse a las fuentes documentales de 
carácter religioso, inspiradas en la devoción a los santos y destinadas a fomentarla, cuyo fin es la edificación espiritual'

Su origen histórico se presenta vinculado a quienes fueron los primeros testimonios heroicos de la fe, los mártires. Aunque, una vez Europa se define como cristiana, serán los ascetas, los confesores y los obispos quienes comparten el protagonismo de estos relatos. A partir de siglos plenomedievales, son los fundadores de las nuevas órdenes religiosas junto con algunos místicos de finales de la Edad Media, a quienes aparecen dedicadas estas obras, principalmente las vitae ${ }^{2}$. Sin embargo, y a pesar de esta transformación de los modelos de santidad, consecuencia directa del contacto con una sociedad religiosa que evoluciona y cambia, toda la literatura consagrada a los santos mantiene unos rasgos comunes que se manifiestan tanto en los perfiles de sus personajes como en su vocabulario y en su estilo. Quizás una de las razones que pueda explicar estos paralelismos sea la poderosa influencia que ejerce las Sagradas Escrituras. Ya que siendo la fuente esencial tanto de la liturgia como del plan de estudio de estos autores, clérigos en su mayoría, era tomada en muchos casos como modelo.

Es cierto que el uso del término hagiographus durante la Edad Media era poco frecuente y será san Isidoro de Sevilla, en el siglo VII, el primero en emplear este sustantivo masculino para referirse a los autores de los libros bíblicos. Con el mismo significado lo siguen empleando Rabano Mauro (+856), Andrés de San Víctor $(+1175)$, o Etienne de Tournai $(+1203)$. Es en 1765, con la aparición del VIII tomo de la Enciclopedia, cuando el vocablo hagiógrafo se define como el autor que trabaja sobre la vida y acción de los santos ${ }^{3}$.

Un progresivo desarrollo del culto a los santos y su extensión a otras iglesias, diferentes a aquella donde se localizaba su tumba, contribuirán a incrementar esta actividad literaria. Sin embargo, aun siendo su propio centro religioso o monasterio el primer foco de producción hagiográfica, e incluso en algunos casos resultado de la mano de algún contemporáneo al santo, ésta no quedará exenta tanto del gusto por el embellecimiento legendario, como de erróneas atribuciones que lógicamente alterarán la verdad histórica. Sin duda,

1 H. DELEHAYE, «Les légendes hagiographiques». Subsidia Hagiographica. $\mathrm{N}^{\circ} 18$. Bruselas, 1955 , p. 2. Siguiendo la tradición bollandiana, Guy Phillipart precisa las dos acepciones del término hagiografía: por una parte, la literaria que engloba una producción escrita muy diversa y que permite la reconstrucción histórica de la memoria de un santo. Y por otra, la disciplina científica que aplicando un método crítico estudia los santos, su historia y su culto. G. PHILLIPART, Histoire de la litterature hagiographique latine et vernaculaire en Occident à 1500. Brepols, 1994.

2 M. DE CERTAU, «Hagiographie». Encyclopedie Universalis. París, 1962. T. VIII, pp. 207-9.

3 G. PHILLIPART, «Hagiographes et hagiographie, Hagiologes et hagiologie». Hagiographica, I, 1994, p. 5.

I Congreso de Historia de la Iglesia

Hispania Sacra 51 (1999) 
se trata de un nuevo género que se nutre de la biografía, del panegírico y de la lección moral ${ }^{4}$.

Desde el punto de vista disciplinar, los primeros en dirigir la atención hacia esta amplia y variada producción documental fueron los jesuitas, quienes con la publicación en 1643 del primer volumen de las Actas Sanctorum por los padres Bolland y Henskens, iniciaban una admirable tarea de recopilación, clasificación y edición de las fuentes hagiográficas, logrando de este modo la más completa síntesis y un útil repertorio. En este mismo ámbito cabe señalar los trabajos de los miembros de la «Société Mabillon» que desde comienzos de siglo dirige su atención a la recopilación de las fuentes de la historia monástica publicadas en la revista Revue Mabillon.

\section{LA HAGIOGRAFIA HISTORIOGRÁFICA}

El creciente interés suscitado por las fuentes hagiográficas en las últimas décadas, ha introducido a los historiadores en un campo que hasta ahora permanecía casi exclusivamente en manos de filólogos 5 . De este modo, se han abierto nuevas vías de estudio en relación con estas figuras emblemáticas en el mundo de las representaciones mentales, en especial por su papel de intermediarios entre el Cielo y la Tierra, los santos. Cabe citar a este respecto algunos trabajos sobre la mentalidad de la hagiografía medieval; el método de trabajo delos hagiógrafos; o bien los medios a los que recurrían estos autores para la elaboración del pasado histórico de los santos ${ }^{6}$.

En relación con esta última idea, es la hagiografía historiográfica la que contribuye a la reconstrucción de la memoria histórica de un santo ${ }^{7}$. Y desde esta perspectiva, uno de los aspectos que se plantean a la hora de iniciar un estudio hagiográfico es en qué medida estas fuentes proporcionan datos válidos a la hora

4 H. DELEHAYE, Les légendes hagiographiques, p. 87

5 Resulta interesante comprobar como esta atención se pone de manifiesto con la celebración de reuniones periódicas de carácter intemacional sobre el tema: Hagiographie, cultures et sacietés (IVXII siècles), celebrado en Nanterte en 1979; Les fonctions des saints dans le monde occidental (III-XII siècles), celebrado en Roma en 1988; Santità e agiographia, celebrado en Génova en 1991.

6 En relación a estos últimos aspectos son significativos los trabajos de P. A. SIGAL, Le travail des hagiographes aux $\mathrm{XI}$ et XII siècle: sources d'information et méthodes de redaction. «Francia», $\mathrm{T}$. 15, 1988, pp. 149-183. O J. L. LE MAîTRE -D. J. DuBors, Sources et méthodes de l' hagiographie médievale. París, 1993; F. DOLBEAU, Les hagiographes au travail: collecte et traitement des documents écrits (IX-XII siècle). Thorbecke, 1992.

7 G. PHILIPPART, Hagiographies, I. Brepols-Tumhout, 1994. p. 13: «Elle (l'hagiographie historiographique) sera réputée telle pourvu que, par la narration, la description, la discussion critique, l'éloge, les considerations générales, le rappel d'événements ou de faits du passé, elle contribue à la constuction de la mémoire historique du saint». 
de conocer el pasado. La documentación disponible es muy variada y los géneros literarios principales son las pasiones de los mártires; las vitae y relatos de milagros; y por último las historias de las reliquias, es decir, inventiones, translationes, adventus, elevationes. Existen también fuentes que pueden clasificarse como «menores»; son piezas específicamente litúrgicas (oraciones de los prefacios de la misa, sermones, letanías, calendarios, bendiciones) que aunque deben ser definidas como hagiográficas carecen de pretensiones históricas ${ }^{8}$.

Sin embargo, y de manera previa se han de tener en cuenta unos presupuestos básicos que eviten errores y confusiones a la hora de la utilización de estos relatos. En primer lugar, toda la producción hagiográfica persigue un mismo fin: suscitar, mantener e incrementar el culto a los santos. De este modo, las vidas, los relatos de milagros y las traslaciones de reliquias suelen estar vinculados a un determinado centro espiritual, que deseoso de atraer peregrinos para mejorar su situación económica, iniciaba una tarea de propaganda a través de la difusión de la fáma de santidad de su patrón o del santo del que poseían las reliquias.

Generalmente, la devoción inicial hacia un santo, mantenida con largueza en la memoria de los hombres, reclamaba tarde o temprano una puesta por escrito que permitiera recordar, sin temor a los límites impuestos por el olvido, los hechos y gestas del patrón a quien dirigían sus plegatias. Entonces comienzan a recogerse los últimos ecos de la tradición y los hagiógrafos, recurriendo con frecuencia a falsas interpolaciones y añadidos, dada la insuficiencia de sus datos, harán lo posible por satisfacer la curiosidad del pueblo ${ }^{9}$. No olvidando que además el hagiógrafo escribe con otra intencionalidad bien definida: la edificación espiritual de su receptor.

En segundo lugar, el uso inmediato de estas obras se circunscribe al mundo litúrgico o bien a la vida monástica. De este modo, los espacios de difusión eran la iglesia durante los oficios sagrados; el capítulo o el refectorio; las escuelas donde se formaban los jovenes clérigos y a quienes los santos se les ponían de ejemplo o modelos para meditar. También entre sus utilidades se encontraba la predicación, tarea destinada tanto a la instrucción del pueblo, desarrollando presupuestos morales y doctrinales, como a su edificación espiritual ${ }^{10}$.

8 G. PHILliPaRT, Hagiographica I, p. 2. Așí desde el punto de vista literario son numerosos los géneros que se incluyen: himnos y visiones, biografias e inscripciones epigráficas, sermones y milagros, invenciones y pasiones, plegarias y juramentos, exempla y prefacios liturgicos, panegíricos y diálogos, letanías y calendarios.

9 H. DELEHAYE, «Cinq leçons sur la méthode hagiographique». Subsidia hagiographica. No 21. Bruselas, 1934, p. 10.

10 B. DE GAIFFIER, «Etudes critiques d'hagiographie et d'iconologie». Subsidia hagiographica. $N^{\circ}$ 43. Bruselas, 1967. «L'hagiographie et son public au XI ème siècle», pp. 475-508. p. 476: «Dès avant le XIème siècle, le culte des saints s'était fait une place dans la vie liturgique. Et bien avant le

$I^{\text {er }}$ Congreso de Historia de la Iglesia

Hispania Sacra 51 (1999) 
Por lo tanto, los relatos hagiográficos no eran elaborados ante todo y exclusivamente como libros históricos destinados a ofrecer información sobre determinado «héroe» de la Cristiandad. Además su valor historiográfico, no dependerá exclusivamente de las fuentes que el autor maneje, sino de la interpretación y del uso que hace de las mismas ${ }^{11}$. Los restos del pasado que podían servir al hagiógrafo eran fundamentalmente la tradición escrita (crónicas, anales, memorias, biografías, inscripciones); la tradición oral (testimonios oculares de contemporáneos, o relatos que circulaban entre las gentes) y tradición figurativa (pinturas, esculturas, reliquias). El trabajo de estos redactores consistía en combinar con ingenio artístico y revestir bajo una forma literaria determinada, tanto los hechos específicos tomados de la historia como los temas panegíricos tomados de la predicación. Logrando finalmente que sus obras oscilen de manera permanente entre la historia eclesiástica y homeliética ${ }^{12}$.

Aunque las indicaciones precisas que nos remite la narración de algún suceso, o el contenido del prólogo nos permiten reconocer cuales han sido las fuentes de información históricas empleadas por el autor. Sin duda, la literatura hagiográfica es la fijación de una tradición oral basada en las leyes del recuerdo y que el hagiógrafo con su trabajo se encarga de no hacer desaparecer ${ }^{13}$.

Sin embargo, y he aquí uno de los primeros problemas planteados, estos autores no estaban bien preparados en el oficio de historiadores, y a pesar de

XIème siècle aussi cette pénétration avait une tendence à s'élargir». Así pues a lo largo del año se intercalaban sus fiestas o conmemoraciones entre los diferentes tiempos litúrgicos. En el caso de España, la lectura hagiográfica en la iglesia aparece documentada a partir del siglo VI, siendo el siglo VI la fecha de inicio para la Galia. Estas lecturas bagiograficas se mantienen en la liturgia mozárabe hasta el siglo XI aunque oficialmente desaparecen del oficio de la misa en el siglo VIII. Normalmente se emplean en el rezo de los maitines como lo prueban la aparición de Pasionarios o de compilaciones destinadas a los oficios distribuidos en Lectiones. También el refectorio era un lugar y momento propicio para este tipo de lecturas, o antes de completas y en el capítulo. F. BAÑos, La hagiografía como género literario en la Edad Media. Tesis léda en la Universidad de Oviedo. 1989.

II El hagiógrafo escribe la bistoria con un fin especial y bien concreto que influye en el carácter de su obra. Pues no relata solo por informar sino antes que nada por edificar. Vid. N. 1, H. DELEHAYE.

12 H. DELEHAYE, Subsidia Hagiographica. No 18, p. 64; F. DOLBEAU, «Les hagiographes au travail: collecte et traitement des documents écrits (IX-XII siècles)». Manuscrits hagiographique et travail des hagiographes. Coord. M. Heinzelman. Thorbecke, 1992, pp. 49-77. p. 56: «Le travail des rédacteurs consiste à doser avec art ces deux ingrédients et oscille en permanence entre l'histoire ecclésiastique et l'homilétique».

13 P. A. SIGAL, «Le travail des hagiographes aux XI et XII siècle: sources d'information et méthodes de redaction». Francia, T. 15, 1988, pp. 149-183. El autor introduce algunos aspectos que separarían estas obras de la historia: por ejemplo, el hecho de introducir testimonios personales, como en el caso de los relatos de milagros de las personas que se vieron favorecidas por ellos. $O$ el no hallar ninguna dificultad en remontarse a un pasado lejano, incluso cuando ese lo conoce únicamente por la tradición oral. 
no disponer con bastante frecuencia de la suficiente documentación, tampoco eran capaces de servirse de ella con claridad. De esta manera, a la hora de emprender su tarea, el hagiógrafo iniciaría un labor de búsqueda de datos, que en gran parte de casos terminaba en la interpolación de episodios tomados de otros relatos. Y en el caso de no tener entre sus manos el trabajo de algún predecesor, las soluciones para proceder a la construcción histórica eran acudir a la imaginación, o aquellos elementos que le parecían verdaderos, así como a otros trabajos que enriqueciesen el suyo ${ }^{14}$.

Por otra parte, parece ser que estos historiadores o panegiristas de los santos no disfrutaban de una especial distinción o singularidad, y su trabajo se consideraba igual que el de los restantes historiógrafos, donde la tradición oral era un elemento primordial para la redacción de acontecimientos recientes y contemporáneos $^{15}$. Sin embargo, para Guy Phillipart estos relatos que por su contenido u objeto quedan consagrados a los santos, se diferencian de otras obras de historia no tanto por' su finalidad moral de «edificar», ni por su credulidad o su gusto por lo maravilloso sino por el papel que representa. Pues el santo «literario» ejerce cuatro funciones: de modelo moral; de héroe, como se le identifica en la imaginería; de intermediario activo entre el cielo y la tierra; de figura representativa de un grupo. Entendido de este modo, el papel que juega en la sociedad es superior ${ }^{16}$.

Finalmente y aun tratándose de documentos históricos y narrativos, que pueden utilizar las mismas técnicas descriptivas de una crónica o acta diplomática, deben ser objeto de una forma particular de crítica ${ }^{17}$. Al mismo tiempo que se han de tener en cuenta ciertas peculiaridades como por ejemplo el hecho de que en ellas lo real y lo imaginario, lo fantástico y lo posible van estrechamente unidos y se ponen al servicio del exemplum.

Los relatos hagiográficos son sin duda para el historiador medieval una documentación inigualable para la reconstrucción de las mentalidades. Pues como considera Jacques Fontaine, «las vitae son la cristalización literaria de una consciencia colectiva». El santo se inserta en la vida de un grupo, iglesia o comunidad, que tiene consciencia de sí misma y se asocia a una figura y a un lugar. Por lo tanto, en el estudio de las mentalidades resulta fundamental poner en relación la obra con el público al que va destinada, pues el modelo de santidad que transmite es aquel que encarna mejor las aspiraciones espirituales de una época y que responde más claramente a las inquietudes escatológicas y

\footnotetext{
14 B. DE GAIFFIER, L'hagiographie et son public au XI siècle, p. 423.

15 F. DOLBEAU, Les hagiographes au travail, pp. 49-50.

16 G. PHILLIPART, Histoire de la literature hagiographique.

17 J. L. LE MAÎTRE -D. J. DUBOIS, Sources et méthodes de l' Hagiographie médievale. París, 1993. Cap. VI.
}

$\mathrm{I}^{\mathrm{er}}$ Congreso de Historia de la Iglesia Hispania Sacra 51 (1999) 
morales de unos individuos. Además los relatos de milagros y las traslaciones destinadas a los fieles de esa iglesia local nos transmiten rasgos de la cultura local, de la sociedad y la vida cotidiana. De este modo, resulta imprescindible a la hora de estudiar un texto hagiográfico conocer o al menos intentar precisar el espíritu, las circunstancias, el medio en las que han sido redactadas así como su propio fin ${ }^{18}$.

\section{LAS BASES HAGIOGRÁFICAS HISPANAS}

Para el estudio del caso hispano se deben tener en cuenta dos aspectos previos: por una parte, la reducida producción hagiográfica aunque en total concordancia con lo que ocurre en otros géneros históricos y literarios; y por otra, el escaso interés historiográfico prestado hacia estas fuentes. A la hora de realizar un recorrido temporal que permita dibujar el panorama hagiográfico peninsular, el punto de partida debe ser el repertorio de fuentes de M. C. Díaz y Díaz. Además se ha de hacer obligada referencia entre otros a los trabajos del profesor Valcárcel quien respecto a los primeros siglos medievales y centrándose en el género literario de las vidas, expone de manera clara y sistemática, los distintos ciclos que se pueden identificar aplicando criterios tanto cuantitativos como cualitativos ${ }^{19}$.

Así en los albores del medievo, el «periodo visigodo», se observa como las vidas de santos conviven con algunas pasiones de mártires, siendo sin duda el exponente más destacado de este periodo la Vita sancti Aemiliani de Braulio de Zaragoza, sobre todo por su posterior influencia y continuación ${ }^{20}$. La invasión musulmana en el siglo VIII abre un periodo en el que paradójicamente los centros de producción escrita no se localizan en ese espacio ad extra de esa realidad política que se conoce con el nombre de Al-Andalus. Sino que por el contrario

18 Ibidem, cap. I

19 M. DíAZ y DíAZ, Index scriptorum latinonum Medii Aevi Hispanorum. Madrid, 1959. (Esta obra se abreviará Index ). Para los primeros siglos medievales destacan los siguientes trabajos: M. C. DIAZ Y DÍAZ, «Passionaires, légendiers et compilations hagiographiques dans le haut Moyen Age». Hagiographie, cultures et sociétes $I V-X I I$. 1981, pp. 49-60; V. VALCÁRCEL, Hagiografia hispanolatina visigotica y medieval (s. VII-XI). I Congreso Nacional de Latín Medieval. León, 1993, pp.191-209. Para el caso de la hagiografía medieval portuguesa, que no se incluirá en este dossier, ver el artículo de J. MATOSso, «Le Portugal de 950 à 1550». Hagiographies II. Brepols-Turnhout, 1996. pp. 83-102.

20 Aparecen nuevas vidas dedicadas a este santo en el siglo XIII: De traslatione reliquiarum beati Aemiliani et liber miraculonum eius. Escrita por Fernando, un monje de san Millán en el siglo XIII, aunque Díaz y Díaz data la obra en el XII. Bibliotheca hagiographique Latine, 102. (Esta obra se abreviará como BHL) Y la Vida de san Millán de la Cogolla, del clérigo poeta Gonzalo de Berceo (1236). 
sus verdaderos artífices fueron los elementos mozárabes, entre los que sobresalen las figuras de los clérigos Eulogio de Córdoba y Paulo Albaro ${ }^{21}$.

Quizás lo más destacado de los siglos siguientes, $\mathrm{X}$ al XII, sea el significativo incremento productivo. Evidentemente, su cuantificación en relación con otras zonas europeas, Francia o Italia, sigue resultando extraordinariamente modesta. Sin embargo, este balance diferenciador no debe explicarse recurriendo al argumento comúnmente esgrimido del «retraso cultural hispánico», aunque desde luego no se deban ignorar las difíciles coyunturas políticas por la que atravesaba la Península. Los protagonistas de estos relatos son los santos obispos y abades que comparten escenario con algunos mártires. Pudiéndose hablar de este modo de una santidad de «función», es decir asociada a una determinada condición social y eclesiástica. Así como de santos admirables que por sus virtudes y por sus prodigios provocan una actitud de constante asombro y veneración entre sus fieles devotos ${ }^{22}$.

Al mismo tiempo, aparecen relatos dedicados a las reliquias, consideradas como la presencia material y tangible del santo entre las gentes cristianas. Las invenciones, traslaciones son una ocasión propicia para la aparición de nuevos relatos donde se refieran los milagros obtenidos con esas reliquias así como su posible origen. Y esta narración de los milagros que ocurren a raíz de estos acontecimientos, permiten comprobar como los sepulcros son los verdaderos ejes catalizadores de la espiritualidad. Incluso se puede hablar de un esfuerzo por legitimizar el espacio sagrado protagonizado por los núcleos monásticos más destacados dentro del panorama peninsular. Estos centros religiosos pasan a ser polos de atracción de fieles, dentro de un espacio local o «universal», en la medida que poseen reliquias y se conoce el poder sobrenatural de ellas, especialmente su poder taumatúrgico. Este factor explica el desarrollo de una importante labor de producción de relatos hagiográficos ${ }^{23}$. Sin embargo, será a

21 Eulogio de Córdoba compuso la célebre Memoriale sanctorum (856) cuyos protagonistas son los mártires como también lo fueron de su Liber apologeticus martyrum (857). Albaro redacta la Viza Eulogii. En ambos hagiógrafos observa V. VARCÁRCEL la influencia de la Vita Aemiliani. Influencias que el mismo autor ha estudiado para el caso de la Vita Dominici Silensis, de Grimaldo (XI) en su trabajo La Vita Dominici Silensis de Grimaldo. Estudio, edición crítica y traducción. Logroño, 1982, pp. 127-8.

22 M. C. DíaZ Y DíAZ, Index. Para el siglo X contabilizamos unos diez textos hagiográficos, cifra que se repite en el XI, pero que encuentra un incremento en el XII (30 textos hagiograficos). En esta última centuria Ios santos a los que se Ie dedican las vidas son en su mayoría obispos: san Raimundo, obispo de Roda, san Pedro obispo de Osma; san Olegario, obispo de Barcelona; san Odón, obispo de Urgell; san Armengol, obispo de Urgell y san Rosendo que Díaz sitúa en el XI. Junto a abades como san Lesme, no incluida en el índice de Díaz y san Ifigo. Aparecen las pasiones de san Vicente, san Claudio y san Lupercio, san Zoilo, santa Eulalia, san Facundo y Primitivo.

23. Historia de arcae sanctae Ovetensis traslatione deque sanctorum reliquis quae in ea asservantur de Pelayo, obispo de Oviedo; o la obra anónima Traslatio reliquiarum Ovetum. Además se

$I^{\text {et }}$ Congreso de Historia de la Iglesia

Hispania Sacra 51 (1999) 
lo largo de la centuria siguiente cuando se pueda apreciar la aparición de nuevos rasgos que permitan definir el próximo momento hagiográfico como «la tímida inflexión del XIII».

\section{LA INFLEXIÓN DEL SIGLO XIII' ${ }^{24}$.}

A primera vista, analizando las fuentes escritas correspondientes a esta centuria, se pueden apreciar una serie de aspectos formales que permiten hablar de innovaciones dentro de la producción hagiográfica hispana. En primer lugar, es a partir de ahora cuando comienzan a traducirse las obras latinas a las lenguas vernáculas, lo cual implicaría una mayor difusión no sólo en el ámbito religioso, dado el escaso nivel cultural del clero, sino también entre los laicos. De la traducción al romance, la obra hagiográfica de Gonzalo de Berceo puede ser quizás el mejor exponente. Aunque también aparecen una vida anónima en castellano dedicada al fundador de los dominicos, o un poema en honor a santa María Egipciaca. Para el caso de la recopilación de «milagros redentores» por la intercesión de santo Domingo de Silos y atribuida al monje Pedro Marín se trata de una redacción directamente en romance ${ }^{25}$. Evidentemente, es una voluntad de catequizar lo que promueve el uso de la lengua vulgar para estas obras. De este modo, actuando como elementos de comunicación esencial, venían a ilustrar las verdades de fe, sirviendo como soportes para el desarrollo de una serie de presupuestos teológicos y ascéticos ${ }^{26}$.

cuenta con dos relatos sobre la traslación de las reliquias de san Vicente de Zaragoza; así como de la traslación de las reliquias de los mártires Claudio, Lupercio y Victorio (BHL, 1835). Por otra parte, Rodolfo, monje de Canión, narra los milagros atribuidos al mártir san Zoilo; y también en este mismo género tenemos noticia de los milagros redentores de Santiago de Compostela,

24 Una de las razones que nos ha llevado a detenernos con especial atención en esta centuria a la hora de realizar este trabajo, ha sido la casi total ausencia de estudios de clasificación y sistematización de fuentes realizados para este periodo. Salvo la excepción del estudio realizado por F. BAÑos, La hagiografía como género literario en la Edad Media, 1989. Y la esperada aparición en Hagiographies del artículo de M. BRIESEMEISTER, «Espagne 1130-1450».

25 Obras hagiograficas de Gonzalo de Berceo: Vida de san Millan de la Cogolla; vida de santo Domingo de Silos; Poema de santa Oria y Pasión de san Lorenzo.

26 F. BAÑos señala algunos ejemplos: el poema anónimo castellano de santa María Egipciaca que insiste en el arrepentimiento (= sacramento de la confesión); el martirio de san Lorenzo, insiste en la fortaleza y firmeza de su fe; o la vida de santo Domingo que Berceo divide en tres libros y aprovecha esta advertencia para una breve exposición del dogma de la santísima Trinidad. Esta relación entre la literatura y la doctrina, o bien su marcado carácter didáctico ha sido también estudiado por Juan Menéndez Peláez en obras como El rimado de Palacio; Libro del Buen Amor; Conde de Lucanor. Otro ejemplo sería la obra de Berceo sobre el Sacrificio de la Misa, en relación directa con ese afán de hacer comprender a los fieles los misterios de la fe y de facilitar de este modo su participación, el autor explica la Misa con figuras alegórico-dramáticas. 
En segundo lugar, aparecen una serie de obras denominadas Legendae novae o Abreviationes, que son compilaciones de pasiones y leyendas antiguas. El ejemplo más destacado y punto de referencia para posteriores composiciones incluso hispanas es la Leyenda dorada del dominico Jacobo de Voragine y de la que aparece una primera copia hispana ya en el mismo siglo XIII ${ }^{27}$. De similares características es la Vita sanctorum de Rodrigo el Cerratense. Así como la Vita sanctorum Christi martyrum et confesorum Hispaniae del canónigo sevillano, Bernardo de Biruhega, quien, bajo las directrices del monarca Alfonso $\mathrm{X}$, recogerá las leyendas de los mártires y confesores ${ }^{28}$. Esta nueva tipología resultaba además muy útil desde el punto de vista práctico, pues por su formato pequeño eran fácilmente manejables. Además de adaptarse mejor a las necesidades del momento, como el uso que de ellas hacían los predicadores y el clero a la hora de la preparación de sermones.

Por otra parte, se destaca una mayor difusión de los relatos hagiográficos que vino especialmente de la mano de los predicadores. Las nuevas órdenes, franciscanos y dominicos fundamentalmente, estaban en perfecta conexión con las disposiciones del lateranense. De esta manera, los predicadores actuaron como activos elementos de apoyo a la Curia, mediante la predicación y el sacramento de la confesion, que son los principales elementos para la instrucción y catequesis del pueblo ${ }^{29}$.

Al mismo tiempo, este hecho ayuda a entender la lógica aparición de un gran número de vidas consagradas a los fundadores de las nuevas órdenes mendicantes o a algunos de sus miembros. Esto suponía una hasta ahora inusitada proximidad espacial y temporal entre el autor, un miembro de su comunidad, y el santo ${ }^{30}$. Quizás estas mismas vidas eran un medio que podía garan-

27 Legenda aurea sanctorum, ms. 119 de la Catedral de Cordoba (Index, $\mathrm{n}^{\circ} 1473$ ). Incluidas más bien dentro de la categoría de Leccionarios tenemos dos obras anónimas en este siglo: Flores sanctorum, que recoge 150 vidas de santos y lecciones para las festividades y una Vita extensa.

28 Index $\mathrm{n}^{\circ} 1360$ y 1490.

29 F. FERNÁNDEZ CONDE, «Religiosidad popular y piedad culta. Aplicación de las reformas del Lateranense» en Historia de la Iglesia de España. Dirg. García Villoslada. T. II. Madrid, 1982, p. 47. Los grandes sínodos como Letrán IV en 1215 o posteriormente del II Concilio de Lyon en 1274, que insite en casi los mismos aspectos que el anterior, evidenciaban las preocupaciones de la Iglesia que se manifestarán también en un marco local con la celebración de sínodos provinciales: Valladolid en 1228 y Lérida 1229. Aquí y de manera reiterada se pretende levar a la práctica los decretos del lateranense: la reforma moral y disciplinar del clero; la comunión y confesión anual; la regulación de los beneficios eclesiásticos.

30 Franciscanos: Juan Gil de Zamora, incluye en su obra Tractatus historiae caconicae et civilis sive liber illustrium personarum de 1282 (Index, $\mathrm{n}^{\circ}$ 1424), las vidas de dos miembros de su orden: fray Antonio de Segovia $(+1278)$ y fray Antonio de Santarem. Además es autor de una Legenda sancti Antonii. Dominicos: Pedro Ferrando (+1254-8) y su Vita sancti Dominici (BHL 2216); Pedro Marsilio (+1327) y Vita sancti Raymundi a Pefiafort. Dos vidas anónimas de los dominicos Pedro

Ir Congreso de Historia de la Iglesia

Hispania Sacra 51 (1999) 
tizar la cohesión de estas nuevas instituciones religiosas recién instaladas en la península Ibérica, a la vez que eran un instrumento de propaganda de esos ideales que los predicadores difundían con la palabra ${ }^{31}$.

Todos estos santos mendicantes son modelos de un nuevo ideal de santidad que busca la identificación con el Cristo evangélico. Se trata de una santidad ligada más a un estilo de vida, la Imitatio Christi, que a una condición social determinada (santos abades, santos monjes, santos reyes, santos obispos...); más inclinada a la moralidad, en relación directa con la reforma gregoriana «hic et nunc» así como a la disciplina moral y la instrucción, que a los milagros. Ese deseo de persuadir y de acentuar la imitabilidad del santo, modelo de comportamiento, se realizaba en parte presentando vidas de santos próximos a su público. De esta manera, sus vidas pretenden alentar al pueblo a una puesta en práctica del ideal evangélico que en el caso de las órdenes pasa a concretarse en tres aspectos: castidad, obediencia y pobreza. Una vez más y a pesar de la continuidad del género hagiográfico el mensaje que transmitían cambia en perfecta sintonía con las modificaciones que afectaban a esa sociedad ${ }^{32}$.

Entre las vidas que se redactan en el siglo XIII, y dejando a un lado a los fundadores de las nuevas órdenes, se contabiliza un número destacado de relatos hagiográficos dedicados a santos con un peso importante en la tradición hispano-latina. Este es el caso de san Millán de la Cogolla, donde dada la situación crítica tanto en el orden económico como disciplinar que atravesaba el cenobio, se produce un despliegue de una tarea propagandística en la que la hagiografía es un recurso idóneo. Así frente a los centros espirituales emergentes y las nuevas devociones, los monjes emilianenses no quieren dejar caer en el olvido la fama de santidad de su patrón. De este modo, su objetivo era reactivar los flujos de peregrinos, entendidos como auténticas vías de ingreso, hacia el ámbito riojano ${ }^{33}$.

González, obispo de Tuy $(+1246)(B H L, 6711)$ y Berengario obispo de Lérida $(+1256)$. Mercedarios: Pedro de Amer $(+1301)$ autor de una vida de san Pedro Nolasco $(+1256)$; Juan de Llers $(+1290)$ y la Vida de san Pedro Nolasco y Vida de santa María de Cenvellón (+1290).

31 A. LINAGE CONDE Y A. OLIVER, «Ordenes religiosas en la baja Edad Media: los mendicantes» Historia de la Iglesia en España. T. II, pp. 116-172. En el caso de la Península Ibérica la coyuntura histórica, la Reconquista, es aprovechada para la expansión de estas órdenes mendicantes, favorecida en la mayor parte de las veces por el poder real. Así Femando III y Doña Berenguela prognueven fundaciones por toda Castilla de dominicos, cuyas primeras noticias datan de 1218 y franciscanos, desde 1217. Otras órdenes que tiene una importante participación activa dentro de la tarea socio-política de la Reconquista y Repoblación de los nuevos territorios son los Trinitarios y los Mercedarios.

32 A. VAUCHEZ, «Saints admirables et saints imitables: les fonctions de l'hagiographie ont-elles changé aux derniers siècles du Moyen Age?», Les fontions des saints dans le monde occidental (IIIXII). Roma, 1991, pp. 162-171.

33 C. Garcia TURza y J. Garcia TURZA, Una nueva visión de la lengua de Berceo a la luz de la documentación emilianense del siglo XIIl, Universidad de la Rioja, 1996. La disminación de las 
Por otro lado, aparecen santos de época goda, cuyas traslaciones de reliquias o hallazgos de las mismas a lo largo de esta centuria, reclaman una tradición escrita que ayude al afianzamiento de su culto. Este es el caso de san Braulio, cuyas reliquias aparecen en Zaragoza en el último cuarto del siglo y de san Idelfonso (+667), cuya traslación a la iglesia de san Pedro en Zamora tiene lugar en $1260^{34}$. Además parece que los hagiógrafos de estos santos «antiguos», cuyas vidas heroicas y sus maravillosos prodigios resultan desconocidos para el común de los fieles, recurrían a una labor de asociación «sobrenatural» de los mismos con figuras santas del pasado muy vinculadas a la ciudad concreta. Así pues son los santos obispos de sus respectivas sedes quienes descubren sus restos: san Valero de Zaragoza los de san Braulio; san Atilano de Zamora los de san Idelfonso. De este modo, lograrían su integración en el culto cívico de las localidades donde quedaban depositados sus restos mortales ${ }^{35}$.

En el caso de estos tres últimos santos hispano-godos de los cuales se redactan vidas en el siglo XIII quizás se pueda suponer que la renovación de su culto y devoción obedezca a un deseo de mantener vivo ese ideal neogoticista y de alentar la idea de recuperación de una unidad que venía a estar representada por la monarquía hispano-goda. Evidentemente, surgen en el seno de un grupo que tiene conciencia de si mismo, y que logra afirmar su sentido de comunidad recurriendo a un pasado común que pueden reconstruir.

Finalmente, se debe destacar el caso de san Isidoro, cuyas reliquias son trasladadas desde Sevilla a León en 1130. Pero es en este momento cuando el

donaciones; los pleitos con instituciones señoriales laicas o eclesíasticas; el progresivo abandono de la protección real y papal explican la coyuntura nada favorable que atravesaba san Millán. Así se entiende la aparición de la obra de Fernando, monje del siglo XIII y autor de una Traslatio sancti Aemiliani et liber miraculorum; y de Gonzalo de Berceo cuya vitae, según Brian Dutton, es una auténtica defensa del falso privilegio de los votos a san Millán, introducido ya por el biógrafo anterior. Aunque para ambos autores «habrá que insistir sobre todo en objetivos artísticos literarios y propósitos religiosos y didáctico-moralizadores como los que animaron a Berceo a dedicar sus poemas entre otras advocaciones a san Millán. Pues en la segunda mitad del XIII, cuando comienza a conocerse su obra en Castilla el monasterio vive enorme dificultades y carencias que se acentúan a medida que nos aproximamos a la centuria siguiente». (p. 33)

34 Juan Gil de Zamora, Traslatio corporis sancti Adelphosi. A este autor franciscano se le atribuye la vida de san Isidro labrador (+1130) (BHL, 4494), la cual resulta innovadora dada la condición social del santo: un campesino que encama el ideal de vida contemplativa basada en la oración y frecuencia de sacramentos. Para Braulio de Zaragoza: De revelationi sancti beati Braulionis episcopis, (Index, $\mathrm{n}^{\mathrm{a}} 1352$ ), del anónimo cesar agustano también autor de una Vita sancti Leandri, Isidori, Fulgentii et Braulionis (BHL 4810) y Legenda de ss. Laurentio, Valerio et Vicentio (BHL, 4774).

35 De este modo, en el corpus hagiográfico del siglo XII aparece una leyenda anónima dedicada a Valerio Caesaragustano episcopus et confesore (Index, $\mathrm{n}^{\circ} 1467$ ) y una Vita Attilani episcopus Zamorensis (BHL 745). Sobre el culto cívico, ver las actas del congreso celebrado en Nanterre, en 1993: $L a$ religion civique à l'époque médievale et moderne (Chrétienté et Islam). École française de Rome, 1995.

$I^{\text {er }}$ Congreso de Historia de la Iglesia

Hispanja Sacra 51 (1999) 
adquiere una verdadera tradición hagiográfica, así aparecen una historia anónima de la traslación y el relato de los milagros escritos por Lucas de Tuy, canónigo de la colegiata isidoriana ${ }^{36}$. Esta obra incluye en sus últimos capítulos la vida del canónigo leonés san Martino $(+1203)$ y como claramente ha demostrado Patrick Henriet obedecen a un programa intelectual orientado a mostrar la superioridad de este santo y del monasterio donde se encuentran sus reliquias, panteón real en manos de canónigos regulares, frente a otros centros religiosos de la península como Santiago de Compostela. Pero su finalidad va más allá de la simple propaganda a un centro religioso, el Tudense persigue «la exaltación de la vida canonial; una apología de la monarquía castellano-leonesa; así como destacar el papel salvífico de los sacramentales y sacramentos» ${ }^{37}$.

Frente a la profusión de vidas, traslaciones de reliquias y relatos de milagros, el tema martirial ocupa menos de un cuarto de la producción hagiográfica, y aún en menor proporción encontramos el mero relato de la pasión. Finalmente, en cuanto a su función las vidas de santos entran al servicio de una nueva pastoral ejercida por los mendicantes, así como continúan sustentando determinados cultos locales. Y respecto a su intención, estas obras mantienen su finalidad edificadora subrayando el ejemplo que los santos proporcionan con sus vidas.

\section{EL EPÍGONO MEDIEVAL ( XIV-XV).}

En estos siglos se acentúan y generalizan los rasgos que se señalaban como peculiares o innovadores de la centuria anterior ${ }^{38}$. De este modo, el latín viene a ser reemplazado casi totalmente por el castellano, e incluso desde finales del XV aparecen obras en catalán y valenciano. Así en valenciano tenemos los siguientes ejemplos: Juan Ruiz de Corella $(+1490)$, Istoria de santa Magdalena y Vida de santa Ana; Jaime Gazull (+1515), La vida de santa María Magdalena en Cobbles; Miguel Pérez (+s. XVI) Vida de sancta Catherina de Sena

36 Translatio sancti Isidorii (BHL, 4491). De miraculi sancti Isidorii (Index, $\mathbf{n}^{\circ} 1228$ ).

37 P. HENRIET, « Hagiographie et politique à Leon au débout du XIIIème siècle; les chanoins réguliers de Saint-Isidore et la prise de Baeza», Revue Mabillon, T. 69. Brepols, 1997, pp. 53-83. p.76: «pour la première fpis peut-être dasn les royaumes hispaniques chrétiens, un texte hagiographique participe d'un projet intelectuel d'envergure. Les Miraculi sancti /sidori sont le chanoin manquant qui unit le De latera vita et Chronicon Mundi. Par une exposé très pédagogique des bienfaits que les saint dispensent aux bons chrétiens, ils illustrent le premier. Par le récit des victoires de l'empeur des "goths» sur I'Islam. Ils completent le second. L'hagiographie n' y est pas seulement soeur de l'historiographie, mais aussi de la theologie».

38 Para estos últimos años del medievo y los inicios de la modernidad resulta de gran utilidad el trabajo de síntesis y recopilación de fuentes realizado por D. DE COURCELLES, «Espagne de 1450 à 1550w, en Hagiographies I. Brepols-Turnhout, 1994, pp. 155-188. 
y Vida de sant Vicent Ferrer o Narciso Visoles y la Vida de sancta Catherina de Sena.

Por otra parte, destaca el número de las vidas de santos vinculados a las nuevas órdenes religiosas ${ }^{39}$. Entre los grandes hagiógrafos del siglo XIV pueden citarse los dominicos Nicolás de Aymerich $(+1399)$ y su Vita fratris Dalmatii Monerii cathalani Praedicatorum Ordini et diocesis gerundensis, o Pedro Marsilio (+1327) con su Vita sancti Raymundi a Peñafort ${ }^{40}$.

Al mismo tiempo, destaca el auge de las compilaciones: para el siglo XIV once de las cuales siete son ya Flores sactorum, tres en castellano, una en catalán y tres en latín copias de la obra de Voragine. En el siglo XV aparecen diecisiete Flores sanctorum, quince en castellano y dos en catalán. Se impone esta nueva forma de compilación, entendida como reunión de abreviationes que siguen como modelo, aunque no estrictamente, la Legenda aurea ${ }^{41}$.

Dejando a parte los copistas de la obra de Voragine, a partir de la segunda mitad del siglo XV se produce una intensa renovación de la actividad cultural, de manos de los miembros de las órdenes dominica y mercedaria, así como de agustinos y jerónimos ${ }^{42}$. Sin embargo, los clérigos, ya fuesen de órdenes religiosas como seculares, no van a ser los únicos a los que se reserve esta tarea y aunque si siguen siendo mayoritarios, aparecen laicos que se lanzan a estas empresas. Es el caso de Diego Rodríguez de Almela (1426?-1492), capellán de la corte y autor de Tratado que se llama compilación de los vitoriosos miraglos del bien aventurado apóstol Santiago. Como también y sobre todo en los áltimos decenios de este siglo aparecen religiosas autoras de obras de carácter contemplativo como Isabel de Villena, abadesa de las Trinitarias de Valencia y su Vita Christi o Teresa de Cartagena ${ }^{43}$.

39 Guillermo Vives, mercedario (+1405): Vida de santa María de Cervellón y Vida de san Pedro Nolasco. Dedicadas a miembros dominicos las obras anónimas: Vita beati Raimundi Lulli (BHL, 7077); Vita sancti Raymundi de Peñaforti (BHL 7070), así como una recopilación de milagros a él atribuidos. Y del dominico Alfonso Bonhome, Vita s. Antonii.

40 Repertorio de Historia de las ciencias eclesiásticas de España T. I. Salamanca, 1967, p. 257. A Nicolás de Aymerich se le atribuyen una vida y relatos de milagros de Raimundo de Peñafort. La referencia de la obra de Pedro Marsilio es BHL, 7071

41 F. BAÑos, La hagiografia como género literario, pp. 74 y 77.

42 El cartujo Jaime Martí (+1503) y la Vida de Santa Catalina de Siena. Los dominicos: Jaime Gil (+1475?) Martyrium Baptiste loanis; y Juan López de Salamanca (+1479): Vida de san Vicente Ferrer, Vida de Santo Domingo. Los mercedarios Juan Martínez, Vida del segundo maestro General de nuestra orden fray Guillén de Bas; Diego de Muros (1405-1492), Vida de los venerables fray Juan de Granada y fray Pedro de Malasanch y Alfonso de Oropesa (+1488) y la Vida de san Juan Crisóstomo. El jerónimo Gonzalo Frías Historia del monasterio de san Jerónimo y vidas y muertes de seis santos varones. El agustino Juan de Sevilla (+1515?) y Vida de san Juan de Sahagún.

43 Repertorio de las ciencias eclesiásticas, pp. 315 y 317.

$I^{\text {er }}$ Congreso de Historia de la Iglesia

Hispania Sacra 51 (1999) 
Dentro de la labor de propaganda ejercida por este tipo de literatura, se puede hacer referencia al caso de san Idelfonso. De este modo, parece ser que la vida que compone en honor a este santo el Beneficiado de Úbeda, fue escrita tras el concilio de Peñafiel (1302) donde se instituye la fiesta del santo para impulsar su devoción. Además teniendo en cuenta que Úbeda y la diócesis de Jaén eran sufragáneas de Toledo, de donde fue prelado Ildelfonso, con toda probabilidad el autor redactaría su obra en Toledo y para el beneficio y propaganda de la ciudad. Años más tarde aparecen nuevas vidas dedicadas a este santo como la de Alfonso Martínez de Toledo (+1470), arcipreste de Talavera o la de Alfonso de Palencia.

Sin embargo, un nuevo fenómeno debe tenerse en cuenta, es la aparición de las historias o las meditaciones de la vida de Cristo y de la Virgen. Estas conocen un gran auge en detrimento de las vidas de santos. Pueden citarse como ejemplos la Vida de Jesucrist del franciscano Francesco Eiximensis (+1409) o la del mercedario Leandro de Murcia; el Tractatus de veritate conceptionis Virginis Mariae y el Tractatus de sanguine Christi del dominico Jaime Gil $(+1475 \text { ? })^{44}$. En relación con estas últimas se encuentra la creciente piedad cristológica y en especial a la Pasión donde quedaba de manifiesto la condición humana del Hijo de Dios. Al mismo tiempo se desarrolla un género de biografías edificantes, que aun no formando parte específica de la literatura hagiográfica no debe olvidarse.

Por último, es notorio como el género de las Pasiones desaparece en beneficio de las vidas, incluso los relatos con tema martirial van adoptando las formas de estas últimas. Además generalmente se trata de composiciones en prosa y raramente en verso ${ }^{45}$.

Finalmente, los rasgos que pueden caracterizar a esta producción de los últimos momentos del medievo hispano sean por una parte su volumen y la variedad temática. Al mismo tiempo que su inusitada difusión gracias a la aparición de la imprenta, tanto en círculos eclesiásticos como laicos contribuyendo a elevar el grado de espiritualidad tanto a nivel personal como entre determinados grupos socio-económicos. En segundo lugar, quizás no se pueda considerar medieval con toda propiedad, pues su peculiaridades anuncian ya las

44 Repertorio de ciencias eclesiásticas, p. 264, 269, 305. Otros ejemplos son: Tractatus de Passione Domini del cartujo Bonifacio Ferrer (+1417) p. 270; p. 275, Devota contemaplaciô del precios cors de Jesuchrist escrito por el presbítero Felipe de Malla (+c.1431); p. 309 la obra del dominico Juan López de Salamanca $(+1479)$ sobre la vida de la Virgen. Por último las obras de Juan Ruiz de Corella $(+1490$ ) sobre la concepción de la Virgen y sobre santa Ana. p. 314.

45 Entre las Pasiones del siglo XIV encontramos la de Gonzalo de Hinojosa, obispo de Burgos, Passio Centollae et Helenae (BHL, 1724). Así como otra anónima dedicada a las mismas vírgenes (BHL,1725). D. DE COURCELLES, «Espagne de 1450 à 1550», p. 156. 
formas y actitudes de la hagiografía de los próximos siglos. Carecen del planteamiento humanista pero se hallan vestigios que indican una nueva vision del mundo, el indicio de cierta secularización de la conciencia del autor, del concepto de la fama, y la difusión de las lenguas vernáculas. Ya desde finales del siglo XV la hagiografía va a conocer una marcada bifurcación entre lo que sería la hagiografía literaria y la historiográfica ${ }^{46}$.

\section{CONSIDERACIONES FINALES}

Indudablemente, las fuentes documentales hagiográficas ofrecen datos para la reconstrucción del pasado histórico pero que aparecen formando parte de una unidad compacta donde resulta difícil aislar el dato verídico del legendario. Siendo productos de una devoción latente a un santo determinado y del cual pretenden mantener su recuerdo, sus fines no son otros que por una parte exaltar la santidad de su protagonista, y por otra inspirar deseos de imitación y de acudir a la protección del santo.

De este modo y aunque el autor del relato tiene como punto de partida la realidad histórica que pondrá por escrito, ésta queda tamizada de manera irreflexiva e inconsciente, por su visión personal de los hechos, abandonando toda posible objetividad. Además siendo su fin la edificación espiritual de sus lectores u oyentes, no dudará en resaltar unos aspectos o unos personajes determinados sobre otros; en introducir sus impresiones; en embellecer o en deformar la verdad e incluso ante ausencia de datos no duda en inventar e imaginar con el fin de dar a su historia una cierta continuidad.

Pero quizás dejando a un lado estas apreciaciones eminentemente prácticas, la hagiografía se puede considerar como un instrumento para hablar de la que es la única y verdadera fuente de santidad ${ }^{47}$.

En definitiva, el punto de arranque de cualquier estudio hagiográfico debe ser conocer el espíritu que las ha inspirado y las ideas que pretende transmitir el autor, teniendo siempre en cuenta la interrelación constante entre el mundo sensible y el sobrenatural. Al mismo tiempo, estas fuentes revelan toda una serie de manifestaciones, gestos, palabras, que traslucen una mentalidad que conecta al individuo con un grupo e integrada por elementos creencias, valores $\mathrm{y}$ actitudes.

46 F. BAÑos, La hagiografía como género literario, pp. 77 y 79.

47 B. DE GAIFFIER, Subsidia hagiographica, n. 43, p. 57 «Toute l'hagiographie n'a de sens que si elle manifeste l'unique source de saintete: Dieu et l'action de son Fils dans le monde.» De este modo H. DElEHAYE considera en Cinq leçons sur la méthode hagiographique, p. 146: «le culte des saints n'est rien s'il n'a pas pour centre celui pour lequel les saints ont vécu et souffert». 